\title{
Long-cycle-life Lithium-sulfur Batteries with Lithium Solvate Ionic Liquids Shiro SEKI, ${ }^{a, b, *}$ Nobuyuki SERIZAWA, ${ }^{b},{ }^{+}$Katsuhito TAKEI, $^{b}$ Yasuhiro UMEBAYASHI, ${ }^{c}$ Seiji TSUZUKI, ${ }^{\mathrm{d}}$ and Masayoshi WATANABE
}

\author{
a Department of Environmental Chemistry and Chemical Engineering, School of Advanced Engineering, \\ Kogakuin University, 2665-1 Nakano-machi, Hachioji, Tokyo 192-0015, Japan \\ b Materials Science Research Laboratory, Central Research Institute of Electric Power Industry (CRIEPI), \\ 2-6-1 Nagasaka, Yokosuka, Kanagawa 240-0196, Japan \\ c Graduate School of Science and Technology, Niigata University, \\ 8050 Ikarashi, 2-no-cho, Nishi-ku, Niigata 950-218, Japan \\ d National Institute of Advanced Industrial Science and Technology (AIST), \\ 1-1-1 Umezono, Tsukuba, Ibaraki 305-8568, Japan \\ e Department of Chemistry and Biotechnology, Yokohama National University, \\ 79-5 Tokiwadai, Hodogaya-ku, Yokohama, Kanagawa 240-8501, Japan
}

* Corresponding author: shiro-seki@cc.kogakuin.ac.jp

\begin{abstract}
The electrochemical properties of a sulfur positive electrode in equimolar glyme-Li salt mixtures were investigated. Cyclic voltammograms indicated that the insertion of $\mathrm{Li}$ into the sulfur/carbon composite electrode took place over at least three steps during the reduction process. In contrast, the broad anodic current suggested that the electrode kinetics for the extraction of Li were relatively slow. Stable charge-discharge operation of the Li-S cell consisting of a Li negative electrode with [Li(triglyme)][bis(trifluoromethanesulfonyl)amide] as the electrolyte was achieved at 800 cycles. This indicates that dissolution of $\mathrm{Li}_{2} \mathrm{~S}_{x}$ into the electrolyte was effectively suppressed in this system.
\end{abstract}

(C) The Electrochemical Society of Japan, All rights reserved.

Keywords : Lithium Solvate Ionic Liquid, Lithium-sulfur Battery, Battery Performance

\section{Introduction}

The use of lithium (Li) secondary batteries in electric vehicles and electric storage devices, as well as in portable electronics, is eagerly anticipated. ${ }^{1}$ To improve the charge-discharge capacity and the energy density of these batteries, Li-sulfur (S) and Li-air batteries have been investigated. ${ }^{2-4}$ Because sulfur forms compounds with $\mathrm{Li}$, and is abundant, inexpensive, and non-toxic, $\mathrm{S}$ is suitable as a positive active material for the $\mathrm{Li}$ secondary battery. The total reaction between $\mathrm{S}$ and $\mathrm{Li}^{+}$is

$$
\mathrm{S}_{8}+16 \mathrm{Li}^{+}+16 \mathrm{e}^{-} \rightarrow 8 \mathrm{Li}_{2} \mathrm{~S}
$$

The theoretical capacity of $\mathrm{S}$ is estimated to be $1,672 \mathrm{mAhg}^{-1}$, which is almost 10 -fold greater than that of other transition metal compounds, such as $\mathrm{Li}_{x} \mathrm{CoO}_{2}\left(0.5<x<1 ; 137 \mathrm{mAh} \mathrm{g}^{-1}\right), \mathrm{Li}_{x} \mathrm{Mn}_{2-}$ $\mathrm{O}_{4}\left(0<x<1 ; 148 \mathrm{mAhg}^{-1}\right)$. However, the $\mathrm{S}$ positive electrode (S-PE) has the following intrinsic drawbacks: volumetric expansion during $\mathrm{Li}$ insertion, low conductivities of $\mathrm{S}$ and $\mathrm{Li}_{2} \mathrm{~S}_{x}(2<x<8$, intermediate), slow electrode kinetics between $\mathrm{S}$ and $\mathrm{Li}_{2} \mathrm{~S}_{x}$, and dissolution of $\mathrm{Li}_{2} \mathrm{~S}_{x}$ from the S-PE into an electrolyte. ${ }^{5}$ The dissolved $\mathrm{Li}_{2} \mathrm{~S}_{x}$ diffuses to the negative electrode (NE) side and is oxidized by the redox shuttle mechanism, which leads to rapid capacity degradation and low Coulombic efficiency of the cell. ${ }^{6,7}$ Highly ordered, nanostructured S/carbon composites, surface coatings, and additives have been investigated in attempts to suppress the dissolution of $\mathrm{Li}_{2} \mathrm{~S}_{x}$ and enhance the conductivity of the cell. ${ }^{8-13}$

Mixtures of Li salts and glyme behave like ionic liquids (ILs) and are classed as "solvate ionic liquids" (SILs). ${ }^{14-16}$ SILs show higher thermal and electrochemical stabilities in comparison with pure

'Present address: Department of Applied Chemistry, Faculty of Science and Technology, Keio University glyme, because the glyme molecule is strongly coordinated to $\mathrm{Li}^{+}$ and forms the stable $[\mathrm{Li}(\text { glyme })]^{+}$complex cation. ${ }^{15}$ Long-cycle-life charge-discharge operations of 400 cycles have been achieved in triglyme $\left(\mathrm{G} 3, \mathrm{CH}_{3}-\mathrm{O}-\left(\mathrm{C}_{2} \mathrm{H}_{4} \mathrm{O}\right)_{3}-\mathrm{CH}_{3}\right)$-based SIL systems. ${ }^{17}$ The dissolution of $\mathrm{Li}_{2} \mathrm{~S}_{x}$ was suppressed in these systems and stable charge-discharge of the $\mathrm{S} /$ carbon composite $\mathrm{PE}$ was achieved because of the low Lewis acidity of $[\mathrm{Li}(\text { glyme })]^{+}$and low Lewis basicity of [TFSA $]^{-18}$ In this paper, the insertion and extraction of $\mathrm{Li}$ on an S-PE in SILs were investigated by cyclic voltammetry under various potential sweep conditions. Moreover, the battery performance of the S-PE was analyzed in relation to the capacity retention and Coulombic efficiency. This study continues the work of a previous report ${ }^{17}$ and aims to assess the practical utility of Li-S batteries.

\section{Experimental}

G3 and LiTFSA (Kishida Chemical) were used to prepare the [Li(G3) $)_{1}$ TFSA] SILs. They were mixed in an equimolar ratio and stirred for more than $24 \mathrm{~h}$. Residual water was removed by immersion of a Li foil in the electrolyte. The characteristics of the Li-S cells were investigated with [S-PE | [Li(G3) $)_{1}$ TFSA] | Li metal $\mathrm{NE}]$ cells. The PE sheet was composed of $\mathrm{S}(56.7 \mathrm{wt} \%$; purity $>99.99 \%$; Kojundo Chemical) as the active material, Ketjenblack (KB, $28.3 \mathrm{wt} \%$; Lion) as the electrically conductive additive, and polyvinyl alcohol $(15.0 \mathrm{wt} \%$; partially saponified, polymerization degree: 3,500$)$ as the binder. These materials were mixed and thoroughly agitated in a homogenizer with $N$-methylpyrrolidone (NMP). The PE paste was uniformly applied to an Al current collector using an automatic applicator. After the NMP was evaporated, the S-PE sheet was compressed using a roll-press machine to increase the packing density and improve the electrical 
conductivity. The electrode thickness after roll-pressing was about $10 \mu \mathrm{m}$, and the electrode loading was approximately $0.53 \mathrm{mg} \mathrm{cm}^{-2}$. The S-PE sheet, polyolefin separator, [Li(G3) ${ }_{1}$ TFSA], and Li-NE were encapsulated in a 2032 coin cell. All steps were carried out in an Ar-filled glovebox $\left(\left[\mathrm{H}_{2} \mathrm{O}\right]<1 \mathrm{ppm}\right)$. The assembled cells were aged at $333 \mathrm{~K}$ for more than $12 \mathrm{~h}$ to ensure sufficient penetration of the electrolyte into the S-PE sheet.

The prepared cells were analyzed by cyclic voltammetry at $303 \mathrm{~K}$ using a electrochemical measurement system (HZ-3000, Hokuto Denko) to clarify the electrochemical properties of the S-PE in the [Li(G3) ${ }_{1}$ TFSA]. Galvanostatic charge-discharge measurements were performed on the cell with the [Li(G3) TFSA] electrolyte using a charge-discharge measurement system (HJ1005SM8A, Hokuto Denko) at $303 \mathrm{~K}$ and $3.3-1.5 \mathrm{~V}$ with a current density of $92.9 \mu \mathrm{A} \mathrm{cm}^{-2} \mathrm{~g}^{-1}-\mathrm{S}$. This corresponds to an $18 \mathrm{~h}$ rate and is denoted as $\mathrm{C} / 18$. A charge-discharge test with a small current $(\mathrm{C} / 100)$ was also conducted at $303 \mathrm{~K}$ for differential analysis. All capacity values in this study were calculated on the basis of the weight of S.

\section{Results and Discussion}

Figure 1 shows the dependence of the cyclic voltammograms (CVs) of the prepared S/KB composite PE in [Li(G3) ${ }_{1}$ TFSA] on the potential sweep rate (a) and the potential region (b). At least three reductive current peaks were observed in $\mathrm{CV}$ (rate: $10 \mu \mathrm{V} \mathrm{s}^{-1}$ ); these corresponded to the gradual $\mathrm{Li}$ insertion into the $\mathrm{S}-\mathrm{PE}$. The reactions in the high $(2.4-2.0 \mathrm{~V})$ and low $(\sim 2.0 \mathrm{~V})$ voltage regions were attributed to the reduction reaction of $\mathrm{S}_{8}$ to $\mathrm{Li}_{2} \mathrm{~S}_{x}$, and $\mathrm{Li}_{2} \mathrm{~S}_{x}$ to $\mathrm{Li}_{2} \mathrm{~S}$, respectively. In contrast, only one broad oxidative current peak with a shoulder, which corresponds to $\mathrm{Li}$ extraction from the lithiated $\mathrm{S}-\mathrm{PE}$, was observed in the reverse scan, even at a scan rate of $10 \mu \mathrm{V} \mathrm{s}^{-1}$. The oxidative peak broadened during the sweep towards lower voltage. Although the depth of the Li doping was shallower for higher potential sweep rates, the oxidative peak broadened with increasing sweep rates. This indicates that the electrode kinetics of the oxidative Li extraction process are slower than those of reductive $\mathrm{Li}$ insertion. The electrochemical properties of active materials were previously investigated using composite electrodes ${ }^{19}$ with severaltypes of specific surface area by inverse opal carbon and these studies showed that the charge-discharge behavior in the Li-S system strongly depends on the composition and structure of the composite electrodes. The current study further shows that the electrode kinetics of $\mathrm{Li}$ extraction are slower than those of $\mathrm{Li}$ insertion on the composite electrodes. It is possible to discuss the $\mathrm{Li}$ insertion and extraction mechanism in these electrolytes in more detail using a single particle. ${ }^{20}$

Figure 2(a) shows the charge-discharge curves of the [S-PE । [Li(G3) ${ }_{1}$ TFSA] | Li metal NE] cell at a current of $92.9 \mathrm{~mA} \mathrm{~g}^{-1}$ sulfur $(1 / 18 \mathrm{C})$. In this report, the initial discharge and charge cycles are defined as the first and second cycles, respectively. Utilization of greater than $50 \%$ indicated that partial reduction to $\mathrm{Li}_{2} \mathrm{~S}$ occurred in this system (initial discharge capacity: $1,060 \mathrm{mAh} \mathrm{g}^{-1}$ ). The discharge curve contained two voltage regions at around 2.3 and $2.0 \mathrm{~V}$, and the differential curve of the discharge at $1 / 100 \mathrm{C}$ is shown in Fig. 2(b). The three $\mathrm{d} Q / \mathrm{d} V$ peaks $(1.91,2.03,2.26 \mathrm{~V})$ suggest that $\mathrm{Li}$ insertion took place over at least three steps, which is consistent with the shown in Fig. 1. In contrast, the charging curve did not show an obvious voltage plateau, which lowered the energy efficiency.

The cycle performance and Coulombic efficiency of the cell are shown in Fig. 3. The Coulombic efficiency was defined as the ratio of the discharge (Li doping into $\mathrm{S}$ ) capacity to the charging ( $\mathrm{Li}$ dedoping of $\mathrm{Li}_{2} \mathrm{~S}_{x}$ ) capacity. The operation was stable at 800 cycles and the Coulombic efficiency of the cell was greater than $97.5 \%$ in all cycles (with a blackout around 400 cycles). The discharge capacity was 821,702 , and $459 \mathrm{mAh} \mathrm{g}^{-1}$ after 200,400 , and 800 cycles, which corresponds to $78 \%, 66 \%$, and $43 \%$ of the initial discharge capacity, respectively. Although there were no radical changes in the design of our composite PE, the stable chargedischarge operation indicates that the dissolution of $\mathrm{Li}_{2} \mathrm{~S}_{x}$ into the electrolyte was suppressed in [Li(G3) $)_{1}$ TFSA], and that the redox shuttle mechanism did not occur. In this system, the low Lewis acidity and basicity of probably $[\mathrm{Li}(\mathrm{G} 3)]^{+}$and $\mathrm{TFSA}^{-}$also effectively suppress the dissolution of $\mathrm{Li}_{2} \mathrm{~S}_{x}$. Optimization of the cell fabrication processes, for example, the PE composition, the roll-press conditions, and current collector, will be investigated in future work. These modifications are expected to further improve the performance of Li-S batteries with SILs.

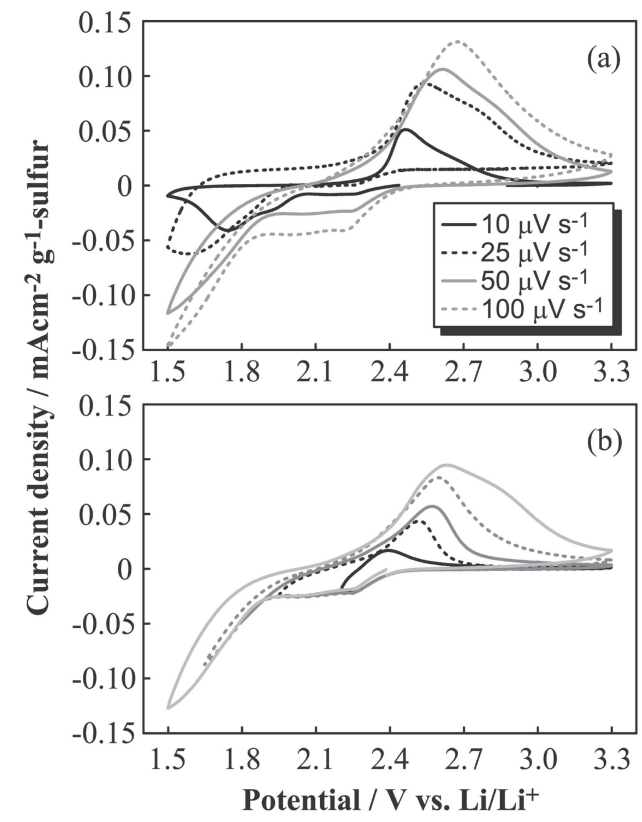

Figure 1. Cyclic voltammograms of a sulfur/carbon composite electrode in [Li(G3) $)_{1}$ TFSA] various potential sweep rates (a) and various lower voltage limits (rate: $50 \mu \mathrm{V} \mathrm{s}^{-1}$ ) (b) at $303 \mathrm{~K}$.
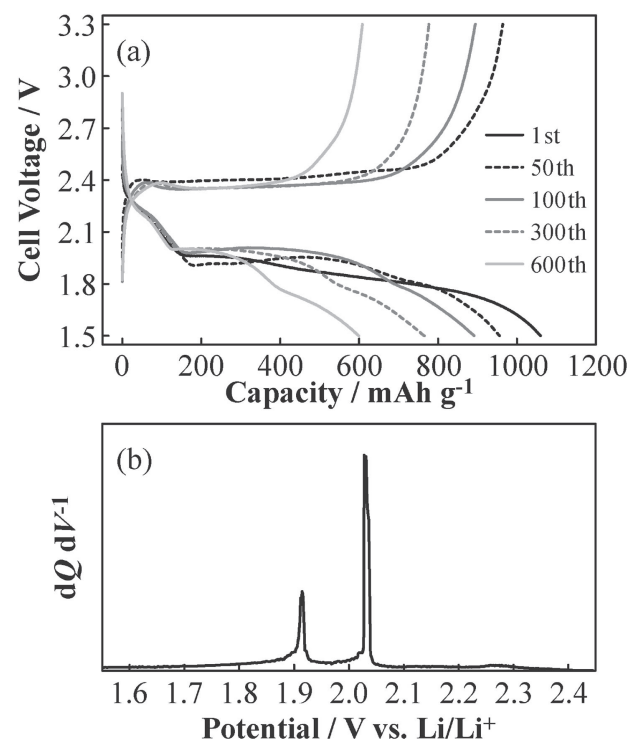

Figure 2. Charge-discharge profiles with $\mathrm{C} / 18$ (a) and differential discharge curve with $\mathrm{C} / 100$ (b) of the [S positive electrode [Li(G3) ${ }_{1}$ TFSA] | lithium metal negative electrode] cell at $303 \mathrm{~K}$. 

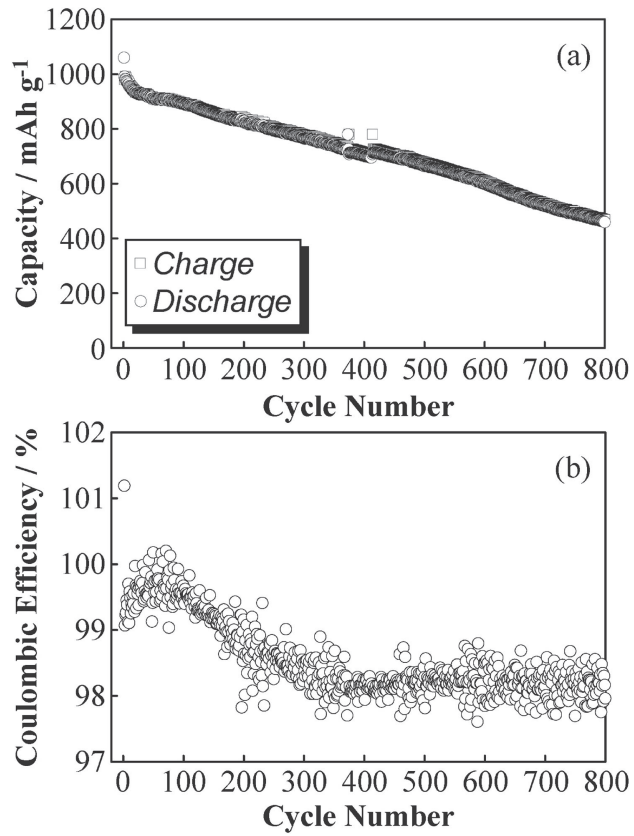

Figure 3. The battery performances of the [S positive electrode | [Li(G3) $)_{1}$ TFSA] | lithium metal negative electrode] cell (a. relationship between cycle number and charge and discharge capacity, b. Coumlombic efficiency).

\section{Conclusion}

Multi-step Li insertion into S-PEs was observed in [Li(G3) $)_{1}$ TFSA], which is consistent with the discharge profile of the Li-S cells. The electrode kinetics of $\mathrm{Li}$ extraction from lithiated $\mathrm{S}$ were slower than those of $\mathrm{Li}$ insertion into $\mathrm{S}$, and utilization of greater than $50 \%$ during discharge suggests the reduction of $\mathrm{S}$ to $\mathrm{Li}_{2} \mathrm{~S}$. Stable cell operation with no major modifications of the $\mathrm{S} / \mathrm{KB}$ composite suggests that the properties of the electrolyte play an important role in suppressing the dissolution of $\mathrm{Li}_{2} \mathrm{~S}_{x}$ and the redox shuttle mechanism. As a result, a favorable charge-discharge operation of 800 cycles was achieved, and we have demonstrated that the SIL concept is effective for the development of Li-S cells.

\section{Acknowledgments}

This work was supported by the Advanced Low Carbon Technology Research and Development Program (ALCA) of the Japan Science and Technology Agency (JST), Japan.

\section{References}

1. J.-M. Tarascon and M. Armand, Nature, 414, 359 (2001).

2. B. Scrosati, J. Hassoun, and Y.-K. Sun, Energy Environ. Sci., 4, 3287 (2011).

3. P. G. Bruce, S. A. Freunberger, L. J. Hardwick, and J.-M. Tarascon, Nat. Mater., 11, 19 (2012).

4. C. Barchasz, F. Mesguich, J. Dijon, J.-C. Leprêtre, S. Patoux, and F. Alloin, J. Power Sources, 211, 19 (2012).

5. R. D. Rauh, F. S. Shuker, J. M. Marston, and S. B. Brummer, J. Inorg. Nucl. Chem., 39, 1761 (1977).

6. J. Shim, K. A. Striebel, and E. J. Cairns, J. Electrochem. Soc., 149, A1321 (2002).

7. Y. V. Mikhaylik and J. R. Akridge, J. Electrochem. Soc., 151, A1969 (2004).

8. X. Ji, K. T. Lee, and L. F. Nazar, Nat. Mater, 8, 500 (2009).

9. T. Takeuchi, H. Sakaebe, H. Kageyama, H. Senoh, T. Sakai, and K. Tastumi, J. Power Sources, 195, 2928 (2010).

10. Y. L. Cao, X. L. Li, I. A. Aksay, J. Lemmon, Z. M. Nie, Z. G. Yang, and J. Liu, Phys. Chem. Chem. Phys., 13, 7660 (2011).

11. G. Zheng, Y. Ynag, J. J. Cha, S. S. Hong, and Y. Chi, Nano Lett., 11, 4462 (2011).

12. J.-W. Choi, G. Cheruvally, D.-S. Kim, J.-H. Ahn, K.-W. Kim, and H.-J. Ahn, J. Power Sources, 183, 441 (2008).

13. D. Aurbach, E. Pollak, R. Elazari, G. Salitra, C. S. Kelley, and J. Affinito, J. Electrochem. Soc., 156, A694 (2009).

14. W. A. Henderson, F. McKenna, M. A. Khan, N. R. Brooks, V. G. Young, and R. Frech, Chem. Mater., 17, 2284 (2005).

15. C. A. Angell, Y. Ansari, and Z. Zhao, Faraday Discuss., 154, 9 (2012).

16. T. Tamura, K. Yoshida, T. Hachida, M. Tsuchiya, M. Nakamura, Y. Kazue, N. Tachikawa, K. Dokko, and M. Watanabe, Chem. Lett., 39, 753 (2010).

17. K. Dokko, N. Tachikawa, K. Yamauchi, E. Takashima, J. Park, K. Ueno, S. Seki, N. Serizawa, and M. Watanabe, J. Electrochem. Soc., 160, A1304 (2013).

18. K. Yoshida, M. Nakamura, Y. Kazue, N. Tachikawa, S. Tsuzuki, S. Seki, K. Dokko, and M. Watanabe, J. Am. Chem. Soc., 133, 13121 (2011).

19. N. Tachikawa, K. Yamauchi, E. Takashima, J.-W. Park, K. Dokko, and M. Watanabe, Chem. Commun., 47, 8157 (2011).

20. K. Dokko, S. Horikoshi, T. Itoh, M. Nishizawa, M. Mohamedi, and I. Uchida, J. Power Sources, 90, 109 (2000). 